\title{
Quality Of Life of Children with Thalassemia in Alexandria
}

\author{
Maha Mabrouk Ali Mahmoud, Nursing Science Teacher Specialist \\ Pediatric Nursing, Technical Health Institute, Alexandria
}

Nadia Medani Helaly, Assistant Professor

Pediatric Nursing, Faculty of Nursing, Alexandria University

\author{
Abeer Abd El-Razik Ahmed Mohammed, Assistant Professor \\ Pediatric Nursing, Faculty of Nursing, Alexandria University \\ Maha Youssef Kamal Mohammed, Assistant Professor \\ Pediatrics, Faculty of Medicine, Alexandria University
}

\begin{abstract}
Thalassemia is one of the most common chronic inherited blood disorder encountered among children worldwide particularly in developing countries. It negatively affects all aspects of children's quality of life (QOL) either physical, emotional or social functioning as well as scholastic achievement. Objective: Assess the quality of life of children with thalassemia at University Children's Hospital in Alexandria. Setting: The study was conducted in the Hematology clinic at the Outpatient Department of Alexandria University Children's Hospital at El-Shatby in Alexandria. Subjects: A convenience sampling of 200 children with thalassemia and their parents who attended the previously mentioned setting and fulfilled the following criteria comprised the study subjects: Confirmed diagnosis with thalassemia, age ranged from 8 to 12 years and free from any other chronic disease. Tools: Two tools were used to collect necessary data namely; Bio-socio-demographic Data of Parents and their Children with Thalassemia Structured Interview Schedule and the Pediatric Quality of Life Scale. Results: Approximately three quarters of children (71.0\%) attained low QOL regarding physical functioning. The vast majority of them (94.5\%) had low QOL concerning social functioning. Additionally, the highest percentages of those children had low QOL in relation to emotional and school functioning ( $87.5 \%$ and $82.5 \%$ respectively). Conclusion: Thalassemia is negatively affecting the children's QOL. Where, the majority of the children and their parents reported low $Q O L$ and the minority of them had moderate QOL. Meanwhile, small percent of them had high QOL. Recommendations: Mass media should raise society awareness regarding thalassemia, and health education sessions with updated simplified brochures and counseling should be conducted for parents.
\end{abstract}

Keywords: Quality Of life; Children with Thalassemia; University Children's Hospital; Alexandria.

\section{Introduction}

Beta-thalassemia is the most common and severe form of thalassemia that is known as thalassemia major or Cooley's anemia $^{(1)}$. It imposes an immeasurable burden on millions of children around the world particularly in developing countries $^{(2,3)}$. Worldwide, thalassemia was estimated to occur in 4.4: 10.000 live births in $(2015)^{(4)}$. It is considered life threatening blood disorder if not properly treated ${ }^{(5)}$.

Children with thalassemia usually need regular blood transfusion for the rest of their life to manage chronic anemia. Regular blood transfusion leads to iron accumulation in organs that may disrupt their functions. So, long- term transfusions should be accompanied by iron chelation therapy. Thalassemia is likely to be one of the great health problems that affects the Quality Of life (QOL) of children ${ }^{(1,6)}$.

Quality Of life is a multidimensional concept that focuses on the impact of disease and its treatment in well-being of an individual. The QOL of children with thalassemia is influenced by many factors. As a chronic illness, thalassemia leads to difficult physical, psychological, academic 
as well as social problems ${ }^{(7)}$. The negative impact of thalassemia on the QOL can be comprised of multiple physical and psychological manifestations. Physically, those children experienced bone deformity, growth retardation, and delayed puberty ${ }^{(5)}$. While, psychological manifestations include depression, anxiety, emotional burden and difficulty with social integration. In addition, it affects school functioning ${ }^{(6,8)}$.

The assessment of QOL in children differs from other forms of assessment in that it focuses on the individual's own view of his well-being and other aspects of life, giving a more holistic view of well-being ${ }^{(9)}$.

Pediatric nurse plays a crucial role in providing care for children with thalassemia. Nursing care should be directed towards following therapeutic regimen to improve their QOL. Moreover, pediatric nurse has to provide parental support and education about the general principles of care for those children. The nurse should also reassure parents with particularly emphasize on potential health problems that may affect the children's QOL. Since the measurement of QOL involves assessment of both the impact of disease process and its treatment modalities in well-being of an individual. So, it is reasonable for pediatric nurse to be aware about the effect of thalassemia and its treatment on children's QOL ${ }^{(4)}$.

\section{Aim of the Study}

The current study aimed to assess the QOL of children with thalassemia at University Children's Hospital in Alexandria.

\section{Research Question}

What is the QOL of children with thalassemia?

\section{Materials and Method}

\section{Materials}

Design: A descriptive research design was used to accomplish this study.
Setting: The study was conducted in the Hematology clinic at the Outpatient Department of Alexandria University Children's Hospital at El-Shatby in Alexandria.

Subjects: The EP Info 7 Program was used to find the sample size using the following Parameters:

- Occlusion size=288 over 3 months.

- Expected frequency $=50 \%$.

- Acceptance error $=50 \%$.

- Confidence coefficient $=95 \%$.

- Minimum sample size $=165$.

A convenience sampling of 200 children with thalassemia and their parents, who attended the previously mentioned setting and fulfilled the following criteria, comprised the study subjects:

- Age ranged from 8 to 12 years.

- Free from any other chronic disease.

Tools: Two tools were used to collect the necessary data:

Tool I: Bio-socio-demographic Data of Parents and their Children with Thalassemia Structured Interview Schedule

This tool was developed by the researcher after thorough review of related literature $^{(1,6,10)}$ to collect the necessary data:

A. Characteristic of Parents: as age, level of education, occupation, consanguinity as well as family income.

B. Characteristic of Children: as age, sex and level of education.

C. Medical History of Children with Thalassemia: as onset of thalassemia, treatment the child receives and number of blood transfusions per month. 


\section{Tool II: The Pediatric Quality of Life Scale (PedsQOL)}

This tool was developed by Varni et al., $1998^{(11)}$. It was adopted by the researcher. It is a modular approach to measure health related quality of life (HRQOL) of children and adolescents in acute and chronic health conditions. This scale consists of 28 Disease-Specific Modules. PedsQOL Thalassemic Module Version 4 was used to assess children's QOL.

PedsQOL Thalassemic Module includes four self-reports which are:

- Young children's report (age ranged from 5 to 7 years).

- Parent's report for young children (age ranged from 5 to 7 years).

- Child's report (age ranged from 8 to 12 years).

- Parent's report for children (age ranged from 8 to 12 years).

The last two reports were used.

There are four domains in each report. The PedsQOL version 4.0 consists of 23 statements including the following:

- Physical functioning (eight statements) as difficulty in running.

- Emotional functioning (five statements) such as sleeping troubles.

- Social functioning (five statements) such as other kids refuse him.

- School functioning (five statements) such as paying attention in class.

The child as well as parents responded to these statements on a five point Likert Scale that ranged from $0-4$ as follows:

Never $=0, \quad$ Almost never $=1$, Sometimes $=2, \quad$ Often $=3, \quad$ and Almost always $=4$.

The scoring system was done concerning the four domains of QOL. The total score was 92. It was divided into physical functioning "32 score", emotional functioning "20 score", social functioning "20 score" and school functioning"20 score". The total scores of health related PedsQOL were transformed into a qualitative manner as follow:

- High quality of life: $75 \%-100 \%$.

- Moderate quality of life: $50 \%$ to less than $75 \%$.

- Low quality of life: $0 \%$ to less than $50 \%$.

\section{Method}

- An official letter was sent from Faculty of Nursing to the director of the Alexandria University Children's Hospital to facilitate research implementation.

- A written approval was obtained from hospital administrative personnel after explaining the aim of the study to collect the necessary data.

- Tool I was developed after thorough review of relevant literature ${ }^{(1,6,10)}$.

- The PedsQOL thalassemia module was adopted from (Varni et al., 1998) ${ }^{(11)}$ and was translated into Arabic language.

- Tool I and tool II were tested for their content validity by five experts in pediatric nursing field.

- Reliability of tools I and II was ascertained using Cronbach Coefficient Alpha Test, where $\mathrm{r}=0.903$ and 0.922 respectively.

- A pilot study was conducted on $10 \%$ of children and their parents to test the clarity and feasibility of the tool. Accordingly, the necessary modifications were done. These children and their parents were excluded from the subjects.

- Every child and his parents were individually interviewed to collect data about their characteristics and medical history of children's disease using tool I. In addition, they were 
asked about children's QOL using tool II.

- The duration of each interview lasted about15-20 minutes.

\section{Ethical considerations:}

- Written informed consent was obtained from all parents after providing appropriate explanation about the purpose of the study and they have the right to withdrawal at any time.

- The parents were ascertained for their data confidentiality \&privacy and anonymity of their children were considered.

\section{Statistical Analysis}

- After data were collected, they were coded and transferred into specially designed formats so as to be suitable for computer feeding. Following data entry, checking and verification processes were carried out to avoid errors during the data entry. Frequency analysis, cross tabulation, and manual revision were all used to detect any errors. The Statistical Package for Social Sciences (SPSS) (Version 22) was utilized for both data presentation and statistical analysis of the results.

- Descriptive measures included: number, percentage, minimum, maximum, arithmetic mean and standard deviation (SD).

- Analytical statistical:

1- Kolmogoro-Chi -Square Test and Monte Carlo Test.

2- Correlation analysis: The spearman correlation efficient (rho) is expressed as the pearson coefficient.

3- The level of significance selected for the present study was $\mathrm{P}<0.05$.

\section{Results}

The characteristics of the studied children with thalassemia are illustrated in table (1). It was apparent that approximately two thirds of children (62.5\%) were from 10 to 12 years. Females constituted more than half of the children's sex (53.5\%). Those who ranked the first birth order constituted $40.5 \%$. Regarding the children's level of education, more than three quarters of the children $(76.5 \%)$ had primary education.

Table (2) summaries QOL of children with thalassemia regarding four domains. As regards physical functioning, it revealed from the table that finding difficulty in taking a bath and hygiene as well as making activities were reported almost always by two thirds of children with thalassemia (69.0\% and $65.5 \%$ respectively). Almost always finding difficulty in walking and doing light chores in home were stated almost always by approximately half of children (49.5\% and $49.0 \%$ respectively).

Regarding emotional functioning, it was noted that almost always feeling afraid and sad or being worried while waiting for medical examination and analysis were reported by $74.5 \%, 74.0 \%$, and $71.0 \%$ of children respectively. In addition, almost always having sleeping troubles and any concerns about what would happen in the future were mentioned by $86.0 \%$ and $78.5 \%$ of children. Concerning social functioning, it was obvious from the table that almost always getting lonely with kids or other kids do not want their friendship or teasing from other kids were stated by $84 \%, 88.5 \%$ and $85.5 \%$ of the children respectively. Also, it was clear from the same table that cannot do things as others and find difficulty when playing with kids were reported almost always by $69.5 \%$ and $60.5 \%$ of the children respectively.

Considering school functioning, it was apparent that finding difficulty in paying attention in class and getting a problem in school work were reported almost always by about three quarters of children $(70 \%$ for each). Moreover, it is sometimes that children missing school due to going to 
doctor or hospital admission were mentioned by $46.0 \%$. While, $66.0 \%$ of children stated almost always that they attained less scholastic achievement level than before.

Table (3) shows parents' report of QOL of their children with thalassemia regarding the four domains. As regards physical functioning, it was obvious that $41.5 \%$ of parents reported that their children had almost always difficulty in walking. Thirty eight and half percent of parents mentioned that their children sometimes find difficulty in running. Almost always find difficulty in making activities was mentioned by $58.5 \%$ of parents. While, sometimes find pain in all body was mentioned by $41.5 \%$ of parents. Almost always find difficulty in taking a bath and hygiene as well as doing light chores in home were reported by $65.5 \%$ and $43.5 \%$ of parents respectively.

In relation to emotional functioning, it revealed that almost always feeling sad or afraid or being worried while waiting for medical examination and analysis were reported by more than half of parents (54.5\%, 55.5\% and $58.5 \%$ respectively). In addition, almost always having sleeping troubles and having any concerns about what would happen in the future were mentioned by $84.5 \%$ and $65.0 \%$ of parents respectively.

Considering social functioning, it was noted that almost always getting a lonely with kids or teasing from other kids or other kids do not want their friendship were reported by $83.5 \%, 85.5 \%$ and $92.5 \%$ of parents respectively. Also, cannot do things as others and find difficulty when playing with kids were almost always mentioned by $68.5 \%$ and $67.0 \%$ respectively of parents. Concerning school functioning, it was apparent that difficulty to paying attention in class and getting a problem in schoolwork were mentioned almost always by $60.0 \%$ and $71.5 \%$ respectively by parents. It is almost sometimes that missing school due to illness or going to doctor or hospital admission were mentioned by $41.5 \%$ of them.
Table (4) presents the reports of QOL levels of children with thalassemia versus their parents' report. It is clear from the table that the children had "low" QOL more than parents' view where the percentages were $(71.0 \%, 82.5 \%$ and $94.5 \%$ for children and $63.0 \%, 79.0 \%$ and $93.5 \%$ for parents regarding physical, school and social functioning respectively. Yet the differences were not statistically significant. The children with thalassemia had "low" QOL in relation to their emotional functioning more than parents' view where the percentage was $87.5 \%$ for children compared to $74.5 \%$ for their parents and the difference was statistically significant $(\mathrm{P}=0.003)$.

The levels of QOL of children with thalassemia and their parents are illustrated in figure (1). It was found that the level of QOL for children was "low" for the vast majority $(91.5 \%)$. It was obvious also from the figure (1) that $85.5 \%$ of parents stated that their children had "low" QOL level.

Table (5) illustrates the correlation between QOL for children with thalassemia total percent scores and their parents' reports regarding each QOL functioning. It is clear from the table that there was a positive correlation and significant associations between children's reports of their QOL and those reported by their parents. Also, positive correlations were found between children and their parents' reports of QOL scores in all QOL functioning where the correlation value ranged between 0.521 to 0.814 .

Table (6) illustrates the relation between children with thalassemia total percent score of QOL and their characteristics. It was noted that there was no statistical significant relation between children total QOL percent score and their characteristics.

\section{Discussion}

Beta thalassemia is the most severe form that requires regular blood transfusion. Additionally, those children require iron chelation therapy to guard against iron overload. As a chronic illness, it imposes 
immense burden not only on the children, but also on the families. Consequently, the principal goal for effective management of thalassemia is to allow children to function with minimal restrictions and enjoy a better $\mathrm{QOL}^{(6)}$.

It is a major public health problem that has profound physical, psychological, social and academic consequences leading to an impaired $\mathrm{QOL}^{(6)}$. The vast majority of children with thalassemia in the current study had "low" QOL level which was supported by the findings obtained by their parents. These could be related to frequent hospital visits for long life treatment that leads to poor school performance, physical pain affecting their activities of daily life, low self -esteem because of physical changes and feeling of stigmatization that leads to social isolation. Similar findings were reported by Sharma et al.,(2017) ${ }^{(12)}$. On contrast, El Dakhakhny et al.,(2011) ${ }^{(9)}$ found that almost half of those children had fair QOL.

Thalassemia is a chronic disease that presents a range of serious physical challenges as bone deformity, growth retardation, delayed puberty, short stature as well as poor self-image ${ }^{(13)}$. So, those children are presumed to be inactive ${ }^{(14)}$.The findings of the present study reflected that almost two thirds of the children had problems with usual physical activities and self-care which was supported by the findings reported by their parents. These results could be related to the regular period of mild anemia just prior to scheduled blood transfusion that limits their exercises capacity. Consequently, it leads to fatigue and general weakness. Additionally, pain in all body contributes to difficult in walking, running as well as doing light chores in home. The findings of Fung et al., $(2015)^{(14)}$ were congruent with present study who found that those children had reduced physical activities.

Thalassemia usually arouses many emotional disorders among children as sadness, fears, worries while waiting for medical examination and concerns about what will happen in the future ${ }^{(15)}$. The findings of the current study reflected that the majority of children had low QOL level considering their emotional state. This result was supported by the findings obtained by their parents. This result could be justified by children's fear from painful procedures and going to hospital for taking their treatment including injections and blood transfusion. In addition, dramatic change in their body image as depressed bridge of nose and protrusion of the upper central incisors could affect their self-esteem. The result of Sharma et al., (2017) ${ }^{(12)}$ were in agreement with the present study as they illustrated that QOL was poor regarding psychological domain across all reports of both children with thalassemia and their parents.

Thalassemia deprives the affected children from the chance to live a normal life. It impacts their social relationship and ability to cope effectively with their daily life activities ${ }^{(15)}$. The results of the current study indicated that the majority of children had low QOL level considering their social function. This result is consistent with the findings obtained by their parents. This could be explained by different reasons as teasing from other peers, changes in body image, children's inability to do things that their peer can do. In addition, the presence of anemia triggers fatigue and feeling of getting tired easily. Similar result was reported by Kaheni et al., (2013) ${ }^{(16)}$.

Chronic illness as thalassemia affects the children's scholastic achievement and causes substantial disruption in their education ${ }^{(15)}$. This is supported by the findings of the current study as the majority of children had poor QOL level concerning school function. This finding was supported by the findings obtained by their parents. This could be due to frequent absenteeism from school due to frequent hospital visits for investigations, monthly blood transfusion and treatment of complications. Additionally, anemia in those children is associated with general weakness and decreased mental alertness, which might 
lead to lack of energy while performing academic activities. Sharma et al., (2017) ${ }^{(12)}$ findings were congreunt with the present study as they found that education is one of the greatest obstacles that face children with thalassemia. In contrast, Saha et al., $(2016)^{(17)}$ found that almost half of those children had fair QOL regarding school domain.

The study findings revealed that there were significant associations and positive correlations between total percent scores of children and their parents' reports in all QOL. These findings may be attributed to that parents' reports of QOL for their children were influenced by their stress level, lack of parents' satisfaction and holding negative attitude concerning thalassemia that may hinder them from dealing appropriately with their children's disease. Consequently, it lowers their QOL. Additionally, almost two- thirds of children were from 10-12 yeas who are competent in communicating their problems. Similar findings were reported by Ismail et al., $(2013)^{(18)}$.

\section{Conclusion}

Based on the findings of the current study, it can be concluded that thalassemia is negatively affecting the children's QOL. Where, the majority of the children and their parents reported low QOL and the minority of them had moderate QOL. Meanwhile, small percent of them had high QOL. There was a positive correlation and significant association between the children's reports and their parents' reports.

\section{Recommendations}

Based upon the findings of the current study, the following recommendations are suggested:

- Mass media should raise society awareness regarding thalassemia and should emphasize the disadvantages of consanguineous marriage.

- Health education sessions with updated simplified brochures and counseling should be conducted for parents to improve their awareness about the disease manifestations.

- Updated guidelines as well as manual booklet for thalassemia management should be provided for parents. 
Table (1): Characteristics of the Studied Children with Thalassemia

\begin{tabular}{|c|c|c|}
\hline Characteristics of Children & No. & $\%$ \\
\hline $\begin{array}{c}\text { Child's age (year) } \\
\qquad \quad 8- \\
\cdot \quad 10-12 \\
\end{array}$ & $\begin{array}{c}75 \\
125\end{array}$ & $\begin{array}{l}37.5 \\
62.5\end{array}$ \\
\hline $\begin{aligned} \text { Sex } & \\
\text { - } & \text { Male } \\
\text { - } & \text { Female }\end{aligned}$ & $\begin{array}{c}93 \\
107\end{array}$ & $\begin{array}{l}46.5 \\
53.5\end{array}$ \\
\hline $\begin{array}{l}\text { Birth order } \\
\text { - } \text { First } \\
\text { - Second } \\
\text { - } \quad \text { Third and more }\end{array}$ & $\begin{array}{l}81 \\
60 \\
59\end{array}$ & $\begin{array}{l}40.5 \\
30.0 \\
29.5 \\
\end{array}$ \\
\hline $\begin{array}{l}\text { Level of Educational } \\
\text { - } \quad \text { Primary education } \\
\text { - } \quad \text { Preparatory education } \\
\end{array}$ & $\begin{array}{c}153 \\
47 \\
\end{array}$ & $\begin{array}{l}76.5 \\
23.5 \\
\end{array}$ \\
\hline
\end{tabular}

Table (2): Quality Of Life of Children with Thalassemia Regarding the Four Domains

\begin{tabular}{|c|c|c|c|c|c|c|c|c|c|c|}
\hline \multirow[t]{2}{*}{ Four Domains } & \multicolumn{2}{|c|}{ Never } & \multicolumn{2}{|c|}{ Almost never } & \multicolumn{2}{|c|}{ Sometimes } & \multicolumn{2}{|c|}{ Often } & \multicolumn{2}{|c|}{$\begin{array}{l}\text { Almost } \\
\text { always }\end{array}$} \\
\hline & No. & $\%$ & No. & $\%$ & No. & $\%$ & No. & $\%$ & No. & $\%$ \\
\hline \multicolumn{11}{|l|}{ Physical functioning } \\
\hline - $\quad$ Finding difficult in walking & 14 & 7.0 & 10 & 5.0 & 68 & 34.0 & 9 & 4.5 & 99 & 49.5 \\
\hline - Finding difficult in running & 28 & 14.0 & 7 & 3.5 & 75 & 37.5 & 11 & 5.5 & 79 & 39.5 \\
\hline - Finding difficult in making activities & 28 & 14.0 & 2 & 1.0 & 32 & 16.0 & 7 & 3.5 & 131 & 65.5 \\
\hline - Finding difficult in lifting something & 67 & 33.5 & 5 & 2.5 & 49 & 24.5 & 10 & 5.0 & 69 & 34.5 \\
\hline - Finding difficult in taking a bath & 14 & 7.0 & 5 & 2.5 & 40 & 20.0 & 3 & 1.5 & 138 & 69.0 \\
\hline - Finding difficult in doing light chores & 32 & 16.0 & 6 & 3.0 & 55 & 27.5 & 9 & 4.5 & 98 & 49.0 \\
\hline - Feeling Pain in all body & 34 & 17.0 & 4 & 2.0 & 75 & 37.5 & 8 & 4.0 & 79 & 39.5 \\
\hline - Getting tired of least effort & 42 & 21.0 & 6 & 3.0 & 67 & 33.5 & 13 & 6.5 & 72 & 36.0 \\
\hline \multicolumn{11}{|l|}{ Emotional functioning } \\
\hline - $\quad$ Feeling afraid & 18 & 9.0 & 3 & 1.5 & 27 & 13.5 & 3 & 1.5 & 149 & 74.5 \\
\hline - Feeling a sad & 19 & 9.5 & 5 & 2.5 & 25 & 12.5 & 3 & 1.5 & 148 & 74.0 \\
\hline - Having sleeping troubles & 3 & 1.5 & 1 & 0.5 & 22 & 11.0 & 2 & 1.0 & 172 & 86.0 \\
\hline - Having any concerns about what & 16 & 8.0 & 1 & 0.5 & 19 & 9.5 & 7 & 3.5 & 157 & 78.5 \\
\hline $\begin{array}{l}\text { - Being worried while waiting for } \\
\text { medical examination and analysis }\end{array}$ & 25 & 12.5 & 3 & 1.5 & 22 & 11.0 & 8 & 4.0 & 142 & 71.0 \\
\hline \multicolumn{11}{|l|}{ Social functioning } \\
\hline - Getting a lonely & 11 & 5.5 & 2 & 1.0 & 15 & 7.5 & 4 & 2.0 & 168 & 84.0 \\
\hline - $\quad$ Other kids do no & 1 & 0.5 & 2 & 1.0 & 19 & 9.5 & 1 & 0.5 & 177 & 88.5 \\
\hline \multicolumn{11}{|l|}{ Friendship } \\
\hline - Teasing from other kids & 2 & 1.0 & 2 & 1.0 & 23 & 11.5 & 2 & 1.0 & 171 & 85.5 \\
\hline - Cannot do things as others & 12 & 6.0 & 0 & 0.0 & 47 & 23.5 & 2 & 1.0 & 139 & 69.5 \\
\hline - Difficulty when playing with kids & 15 & 7.5 & 3 & 1.5 & 58 & 29.0 & 3 & 1.5 & 121 & 60.5 \\
\hline $\begin{array}{l}\text { School functioning } \\
\text { - Difficulty in paying attention in class }\end{array}$ & 5 & 2.5 & 5 & 2.5 & 48 & 24.0 & 2 & 1.0 & 140 & 70.0 \\
\hline - Getting a problem in school work & 8 & 4.0 & 7 & 3.5 & 36 & 18.0 & 9 & 4.5 & 140 & 70.0 \\
\hline - Missing school due to illness & 14 & 7.0 & 67 & 33.5 & 87 & 43.5 & 24 & 12.0 & 8 & 4.0 \\
\hline $\begin{array}{l}\text { - Missing school due to going to doctor } \\
\text { Or hospital admission }\end{array}$ & 14 & 7.0 & 65 & 32.5 & 92 & 46.0 & 21 & 10.5 & 8 & 4.0 \\
\hline $\begin{array}{l}\text { - Attaining less scholastic achievement } \\
\text { level than before }\end{array}$ & 5 & 2.5 & 7 & 3.5 & 45 & 22.5 & 11 & 5.5 & 132 & 66.0 \\
\hline
\end{tabular}


QOL, Thalassemia Children

Table (3): Parents' Report of Quality Of Life of their Children with Thalassemia Regarding their Four Domains

\begin{tabular}{|c|c|c|c|c|c|c|c|c|c|c|}
\hline \multirow[t]{2}{*}{ Four Domains } & \multicolumn{2}{|c|}{ Never } & \multicolumn{2}{|c|}{$\begin{array}{c}\text { Almost } \\
\text { never }\end{array}$} & \multicolumn{2}{|c|}{ Sometimes } & \multicolumn{2}{|c|}{ Often } & \multicolumn{2}{|c|}{$\begin{array}{l}\text { Almost } \\
\text { always }\end{array}$} \\
\hline & No. & $\%$ & No. & $\%$ & No. & $\%$ & No. & $\%$ & No. & $\%$ \\
\hline \multicolumn{11}{|l|}{ Physical functioning } \\
\hline - Finding difficult in & 17 & 8.5 & 9 & 4.5 & 79 & 39.5 & 12 & 6.0 & 83 & 41.5 \\
\hline - Finding difficult in running & 25 & 12.5 & 8 & 4.0 & 77 & 38.5 & 16 & 8.0 & 74 & 37.0 \\
\hline - Finding difficult in making activities & 29 & 14.5 & 6 & 3.0 & 39 & 19.5 & 9 & 4.5 & 117 & 58.5 \\
\hline - Finding difficult in lifting something & 84 & 42.0 & 8 & 4.0 & 60 & 30.0 & 6 & 3.0 & 42 & 21.0 \\
\hline - Finding difficult in taking a bath & 15 & 7.5 & 4 & 2.0 & 47 & 23.5 & 3 & 1.5 & 131 & 65.5 \\
\hline - Finding difficult in doing light chores & 39 & 19.5 & 5 & 2.5 & 61 & 30.5 & 8 & 4.0 & 87 & 43.5 \\
\hline - Feeling Pain in all body & 47 & 23.5 & 7 & 3.5 & 83 & 41.5 & 18 & 9.0 & 45 & 22.5 \\
\hline - Getting tired & 71 & 35.5 & 8 & 4.0 & 61 & 30.5 & 19 & 9.5 & 41 & 20.5 \\
\hline \multicolumn{11}{|l|}{ Emotional functioning } \\
\hline - $\quad$ Feeling afraid & 47 & 23.5 & 4 & 2.0 & 33 & 16.5 & 5 & 2.5 & 111 & 55.5 \\
\hline - Feeling a sad & 47 & 23.5 & 4 & 2.0 & 34 & 17.0 & 6 & 3.0 & 109 & 54.5 \\
\hline - Having sleeping troubles & 4 & 2.0 & 3 & 1.5 & 22 & 11.0 & 2 & 1.0 & 169 & 84.5 \\
\hline $\begin{array}{l}\text { - Having any concerns about what would } \\
\text { happen in the future }\end{array}$ & 32 & 16.0 & 2 & 1.0 & 33 & 16.5 & 3 & 1.5 & 130 & 65.0 \\
\hline $\begin{array}{l}\text { - Being worried while waiting for } \\
\text { medical examination an analysis } \\
\text { Social functioning }\end{array}$ & 48 & 24.0 & 2 & 1.0 & 23 & 11.5 & 10 & 5.0 & 117 & 58.5 \\
\hline - Getting a lonely with kids & 10 & 5.0 & 1 & 0.5 & 18 & 9.0 & 4 & 2.0 & 167 & 83.5 \\
\hline - $\quad$ Other kids do $n$ & 2 & 1.0 & 1 & 0.5 & 11 & 5.5 & 1 & 0.5 & 185 & 92.5 \\
\hline \multicolumn{11}{|l|}{ Friendship } \\
\hline - Teasin & 5 & 2.5 & 1 & 0.5 & 23 & 11.5 & 0 & 0.0 & 171 & 85.5 \\
\hline - Cannot do things as others & 9 & 4.5 & 2 & 1.0 & 41 & 20.5 & 11 & 5.5 & 137 & 68.5 \\
\hline - Finding difficulty when playing with kids & 6 & 3.0 & 2 & 1.0 & 54 & 27.0 & 4 & 2.0 & 134 & 67.0 \\
\hline $\begin{array}{l}\text { - Finding difficulty to paying attention in } \\
\text { class }\end{array}$ & 15 & 7.5 & 5 & 2.5 & 55 & 27.5 & 5 & 2.5 & 120 & 60.0 \\
\hline - Getting a problem in school work & 11 & 5.5 & 8 & 4.0 & 34 & 17.0 & 4 & 2.0 & 143 & 71.5 \\
\hline - Missing school due to illness & 12 & 6.0 & 71 & 35.5 & 83 & 41.5 & 31 & 15.5 & 3 & 1.5 \\
\hline $\begin{array}{l}\text { - Missing school due to going to doctor Or } \\
\text { hospital admission }\end{array}$ & 12 & 6.0 & 71 & 35.5 & 83 & 41.5 & 31 & 15.5 & 3 & 1.5 \\
\hline $\begin{array}{l}\text { Attaining less scholastic achievement level } \\
\text { than before }\end{array}$ & 15 & 7.5 & 18 & 9.0 & 50 & 25.0 & 8 & 4.0 & 109 & 54.5 \\
\hline
\end{tabular}


QOL, Thalassemia Children

Table (4): Reports of Quality Of Life Levels of Children with Thalassemia versus their Parents' Reports

\begin{tabular}{|c|c|c|c|c|c|c|}
\hline \multirow[t]{2}{*}{ QOL levels } & \multicolumn{2}{|c|}{$\begin{array}{l}\text { Children } \\
(n=200)\end{array}$} & \multicolumn{2}{|c|}{$\begin{array}{l}\text { Parents } \\
(\mathbf{n}=200)\end{array}$} & \multirow{2}{*}{$\begin{array}{c}\text { Test of } \\
\text { Significance }\end{array}$} & \multirow[t]{2}{*}{$\mathbf{P}$} \\
\hline & No. & $\%$ & No. & $\%$ & & \\
\hline $\begin{array}{l}\text { 1. Physical functioning } \\
\text { Low }(<50)\end{array}$ & 142 & 71.0 & 126 & 63.0 & \multirow{3}{*}{$\begin{array}{c}\chi^{2}= \\
5.455\end{array}$} & \multirow{3}{*}{0.065} \\
\hline Moderate $(50-<75)$ & 43 & 21.5 & 45 & 22.5 & & \\
\hline $\operatorname{High}(\geq 75)$ & 15 & 7.5 & 29 & 14.5 & & \\
\hline $\begin{array}{l}\text { 2. Emotional functioning } \\
\text { Low }(<50)\end{array}$ & 175 & 87.5 & 149 & 74.5 & \multirow{3}{*}{$\begin{array}{c}\chi^{2}= \\
11.856^{*}\end{array}$} & \multirow{3}{*}{$0.003^{*}$} \\
\hline Moderate $(50-<75)$ & 19 & 9.5 & 33 & 16.5 & & \\
\hline $\operatorname{High}(\geq 75)$ & 6 & 3.0 & 18 & 9.0 & & \\
\hline 3. Social functioning & & & & & \multirow{4}{*}{$\begin{array}{c}\chi^{2}= \\
1.544\end{array}$} & \multirow{4}{*}{$\begin{array}{l}{ }_{\mathrm{MC}}= \\
0.507\end{array}$} \\
\hline Low $(<50)$ & 189 & 94.5 & 187 & 93.5 & & \\
\hline Moderate $(50-<75)$ & 7 & 3.5 & 11 & 5.5 & & \\
\hline $\operatorname{High}(\geq 75)$ & 4 & 2.0 & 2 & 1.0 & & \\
\hline $\begin{array}{l}\text { 4.School functioning } \\
\text { Low }(<50)\end{array}$ & 165 & 82.5 & 158 & 79.0 & \multirow{3}{*}{$\begin{array}{c}\chi^{2}= \\
0.812\end{array}$} & \multirow{3}{*}{0.666} \\
\hline Moderate (50 - < 75) & 28 & 14.0 & 33 & 16.5 & & \\
\hline $\operatorname{High}(\geq 75)$ & 7 & 3.5 & 9 & 4.5 & & \\
\hline
\end{tabular}

$\chi^{2}, p: \chi^{2}$ and $p$ values for Chi square test for comparing between the two groups

${ }^{M C}$ : $p$ value for Monte Carlo for Chi square test for comparing between the two groups

* Statistically significant at $p<0.05$

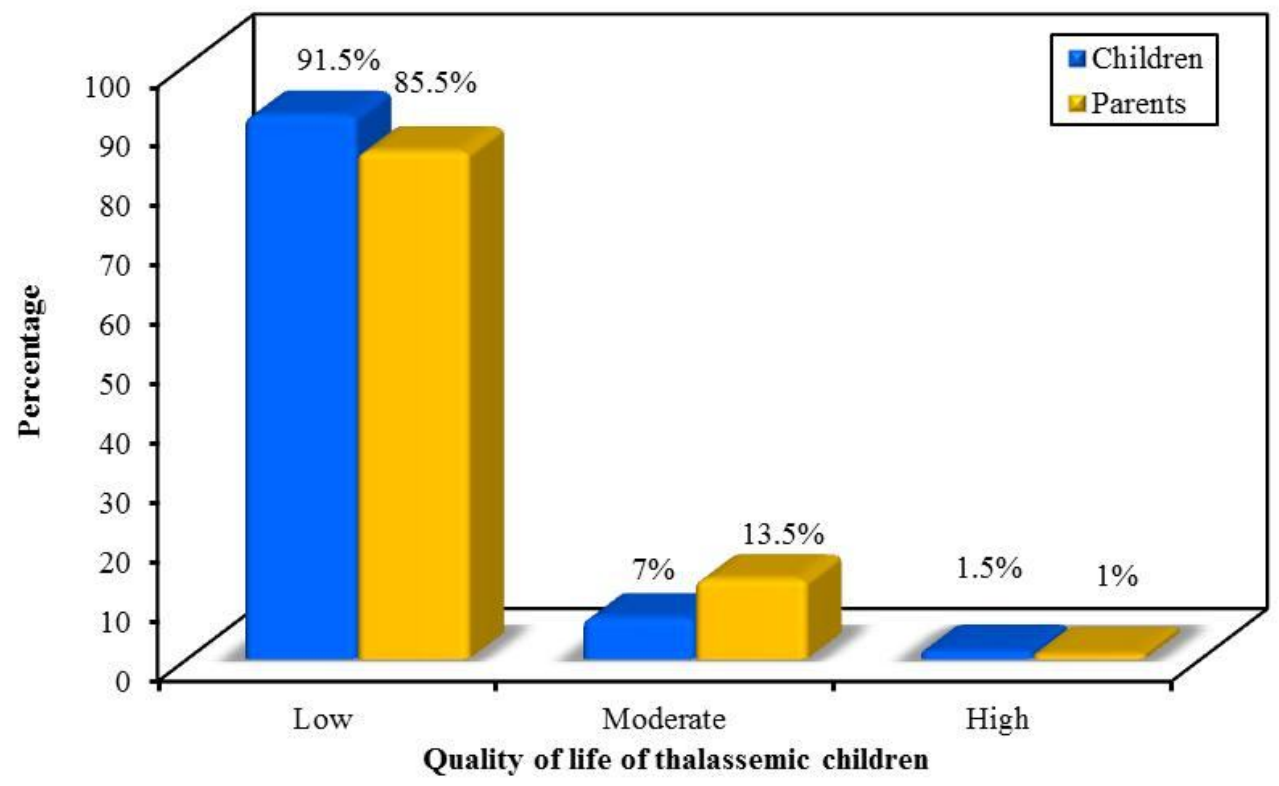

Figure (1): Levels of Quality Of Life of Children with Thalassemia and their Parents 
Table (5): Correlation between Quality of Life for Children with Thalassemia Total Percent Scores and their Parents' Reports Regarding Each Quality of Life Functioning

\begin{tabular}{|c|c|c|}
\hline \multirow{2}{*}{ Items } & \multicolumn{2}{|c|}{ Parent' QOL levels } \\
\hline & $\mathbf{R}$ & $\mathbf{P}$ \\
\hline 1. Physical function & $0.728^{*}$ & $<0.001$ \\
\hline 2. Psychological and emotional function & $0.521^{*}$ & $<0.001$ \\
\hline 3. Social function & $0.686^{*}$ & $<0.001^{*}$ \\
\hline 4.School function & $0.814^{*}$ & $<0.001^{*}$ \\
\hline Total & $0.773^{*}$ & $<0.001^{*}$ \\
\hline
\end{tabular}

r: Pearson coefficient

*: Statistically significant at $p<0.05$

Table (6): Relation between Children with Thalassemia Total Percent Score of QOL and their Characteristics

\begin{tabular}{|c|c|c|c|c|c|c|c|c|}
\hline \multirow{3}{*}{ Children's Characteristics } & \multicolumn{6}{|c|}{ Children's QOL levels } & \multirow{3}{*}{$\chi^{2}$} & \multirow{3}{*}{${ }^{\mathrm{MC}} \mathbf{p}$} \\
\hline & \multicolumn{2}{|c|}{$\begin{array}{c}\text { Low }(<50) \\
(n=183)\end{array}$} & \multicolumn{2}{|c|}{$\begin{array}{c}\text { Moderate } \\
(50-<75) \\
(n=14)\end{array}$} & \multicolumn{2}{|c|}{$\begin{array}{l}\text { High }(\geq 75) \\
\quad(\mathbf{n}=\mathbf{3})\end{array}$} & & \\
\hline & No. & $\%$ & No. & $\%$ & No. & $\%$ & & \\
\hline Sex & & & & & & & & \\
\hline Male & 88 & 94.6 & 3 & 3.2 & 2 & 2.2 & & \\
\hline Female & 95 & 88.8 & 11 & 10.3 & 1 & 0.9 & 4.235 & 0.096 \\
\hline Child's age (Year) & & & & & & & & \\
\hline $8-$ & 72 & 96 & 3 & 4 & 0 & 0.0 & & \\
\hline $10-12$ & 111 & 88.8 & 11 & 8.8 & 3 & 2.4 & 3.201 & 0.195 \\
\hline Birth order & & & & & & & & \\
\hline First & 75 & 92.6 & 5 & 6.2 & 1 & 1.2 & & \\
\hline Second & 55 & 91.7 & 3 & 5 & 2 & 3.3 & 3.128 & 0.546 \\
\hline Third and more & 53 & 89.8 & 6 & 10.2 & 0 & 0.0 & & \\
\hline Level of educational & & & & & & & & \\
\hline Illiterate & 0 & 0.0 & 0 & 0.0 & 0 & 0.0 & & \\
\hline Read and write & 0 & 0.0 & 0 & 0.0 & 0 & 0.0 & 4.478 & 0.092 \\
\hline Primary student & 143 & 93.5 & 9 & 5.9 & 1 & 0.6 & $4.4 / 8$ & 0.092 \\
\hline Preparatory student & 40 & 85.1 & 5 & 10.6 & 2 & 4.3 & & \\
\hline
\end{tabular}

$\chi^{2}, p: \chi^{2}$ and $p$ values for Chi square test

${ }^{M C} p$ : $p$ value for Monte Carlo for Chi square test

*Statistically significant at $p<0.05$ 


\section{References}

1. Rown S, Nelson K, Ashwill A. Nursing Care of Children: Principles and Practices $4^{\text {th }}$ ed. Louis: Elsevier Inc., $2013 ; 580-2$.

2. Hockenberry M, Wilson D. Wong's Nursing Care of Infants and Children $10^{\text {th }}$ ed. St. Louis: Elsevier Inc., 2015; 1349-51.

3. Kamal S. Hepatitis C infection in patients with hemoglobinpathies. In: S. Kamal (Ed.), Hepatitis C in Developing Countries: Current and Future Challenges. London: Elsevier Inc., 2018; 180-1.

4. Elsayed A, Mahmoud S. Nursing Guidelines for Children Suffering from Beta Thalassemia. Journal of Nursing Science 2015; 5(4): 131-5.

5. Thavorncharoensap M, Torcharus K, Nuchprayoon I, Riewpaiboon A, Indaratna K, Ubol B. Factors affecting health-related quality of life in Thai children with thalassemia. BMC Hematology 2010; 10(1): 1 .

6. Wahyuni MS, Ali M, Rosdiana N, Lubis B. Quality of life assessment of children with thalassemia. Paediatrica Indonesiana 2011; 51(3): 163-9.

7. Baghianimoghadam MH, Sharifirad G, Rahaei Z, Baghianimoghadam B, Heshmati $H$. Health related quality of life in children with thalassaemia assessed on the basis of SF-20 questionnaire in Yazd, Iran: a case-control study. Central European Journal Of Public Health 2011; 19(3): 165-9.

8. Ayoub MD, Radi SA, Azab AM, Abulaban AA, Balkhoyor AH, Bedair SW, Kari JA. Quality of life among children with betathalassemia major treated in Western Saudi Arabia. Saudi Medical Journal 2013; 34(12): 1281-6.

9. El Dakhakhny AM, Hesham MA, Mohamed SE, Mohammad FN. Quality of life of school age thalassemic children at Zagazig City. Journal of American Science 2011; 7(1):186-97.

10. Shaker WH, Nasir KM. Determination of Quality of Life for Thalassemic Adolescent. kufa Journal for Nursing Sciences 2013 3(2): 222- 7.
11. Varni JW, Seid M, Rode CA. The PedsQL: measurement model for the pediatric quality of life inventory. Medical Care 1998; 37(2): 126-39.

12. Sharma S, Seth B, Jawade $P$, Ingale $M$, Setia MS. Quality of life in children with thalassemia and their caregivers in India. The Indian Journal of Pediatrics 2017; 84(3):188-94.

13. Behdani F, Badiee Z, Hebrani P, Moharreri $\mathrm{F}$, Badiee $\mathrm{AH}$, Hajivosugh $\mathrm{N}$, Akhavanrezayat A. Psychological aspects in children and adolescents with major thalassemia: a case-control study. Iranian Journal of Pediatrics 2015; 25(3).

14. Fung EB, Pinal J, Leason M. Reduced physical activity patterns in patients with thalassemia compared to healthy controls. Journal of Hematology and Oncology Research 2015; 2(1): 7.

15. Siddiqui SH, Ishtiaq R, Sajid F,Sajid R. Quality of life in patients with thalassemia major in a developing country. JCPSP: Journal of the College of Physicians and Surgeons-Pakistan 2014; 24(7): 477.

16. Kaheni S, Yaghobian M, Sharefzadah GH, Vahidi A, Ghorbani H, Abderahemi A. Quality of life in children with $\beta$ thalassemia major at center for special diseases. Iranian Journal of Pediatric Hematology and Oncology 2013; 3(3): 108.

17. Saha R, Misra R, Saha I. School functioning activity of Bengali thalassemic children attending a tertiary care hospital of eastern India. International Journal of Travel Medicine and Global Health 2016; 4(3): 82-7.

18. Ismail AM, Chun YC, Yusoff MA, Manaf ZA, Rajikan R, Latif A, Jamal AR. Quality of life and their caregiver. Sainsmalaysiana Journal 2013; 42(3):373-80. 